Filippo Boroli

Eva Niyibizi

Karim Bendjelid

\title{
Left upper lobe partial anomalous pulmonary \\ venous return

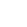

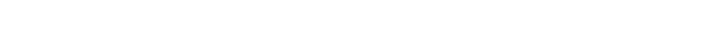

Received: 5 November 2014

Accepted: 20 November 2014

Published online: 2 December 2014

(C) Springer-Verlag Berlin Heidelberg and ESICM 2014

F. Boroli $(\bullet) \cdot$ E. Niyibizi $\cdot$ K. Bendjelid

Intensive Care Service, University Hospital of Geneva, Rue Gabrielle-Perret-Gentil No 4, 1211 Geneva 14, Switzerland e-mail: filippo.boroli@hcuge.ch

Tel.: +41223729096

E. Niyibizi

e-mail: eva.niyibizi@gmail.com

Tel.: +41223729096
K. Bendjelid

e-mail: karim.bendjelid@hcuge.ch Tel.: +41223729096

A nonagenarian woman, known for systemic arterial hypertension and chronic obstructive pulmonary disease, was hospitalized in our ICU for hypoxemic respiratory failure due to community-acquired pneumonia. She was initially treated with antibiotics and noninvasive ventilation. The patient then developed septic shock. A central venous catheter was therefore inserted into the left internal jugular vein (LIJV) under ultrasound guidance.
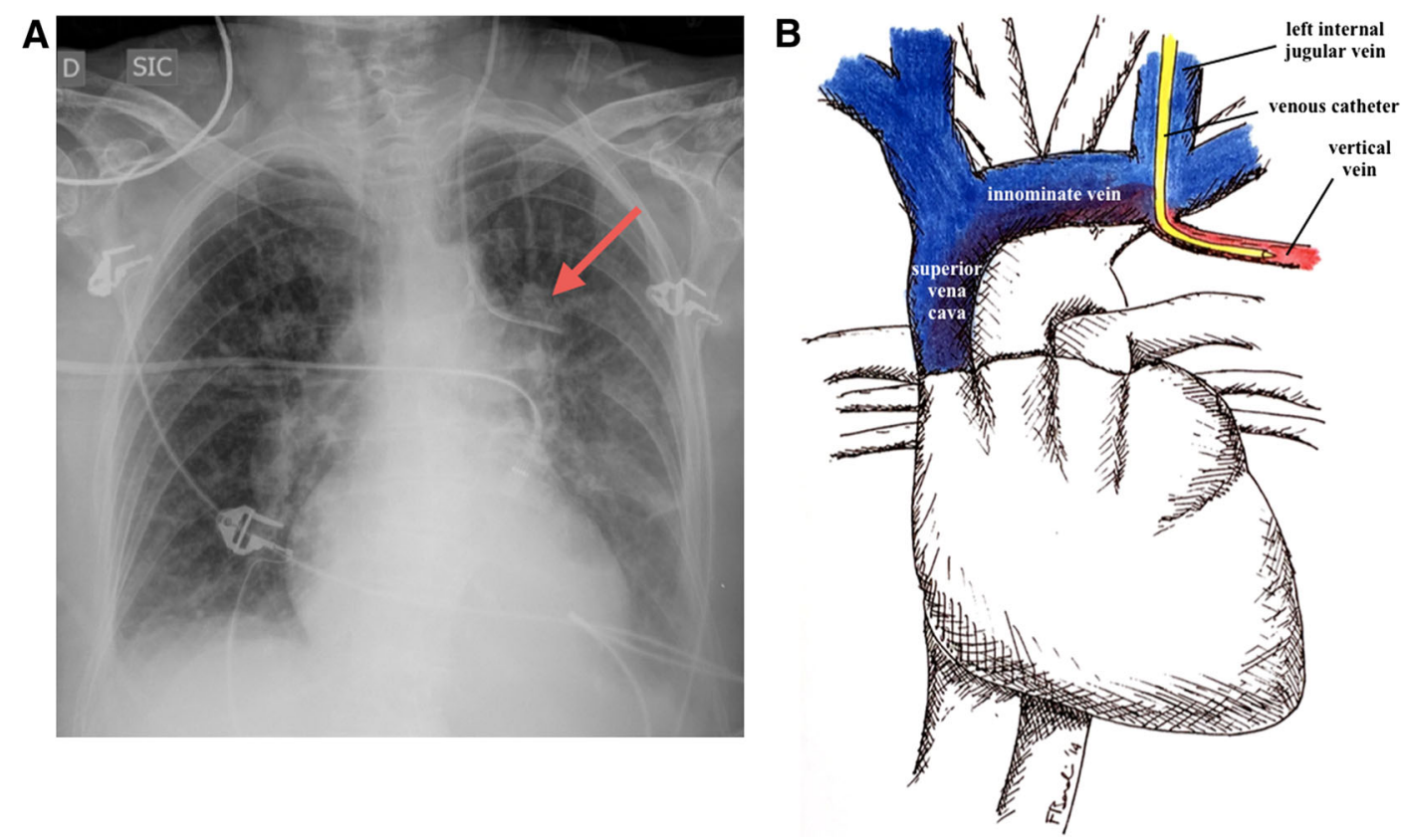

Fig. 1 Chest X-ray showing a catheter above the left main bronchus (a, arrow) and anatomical drawing (b) indicating the catheter tip location 


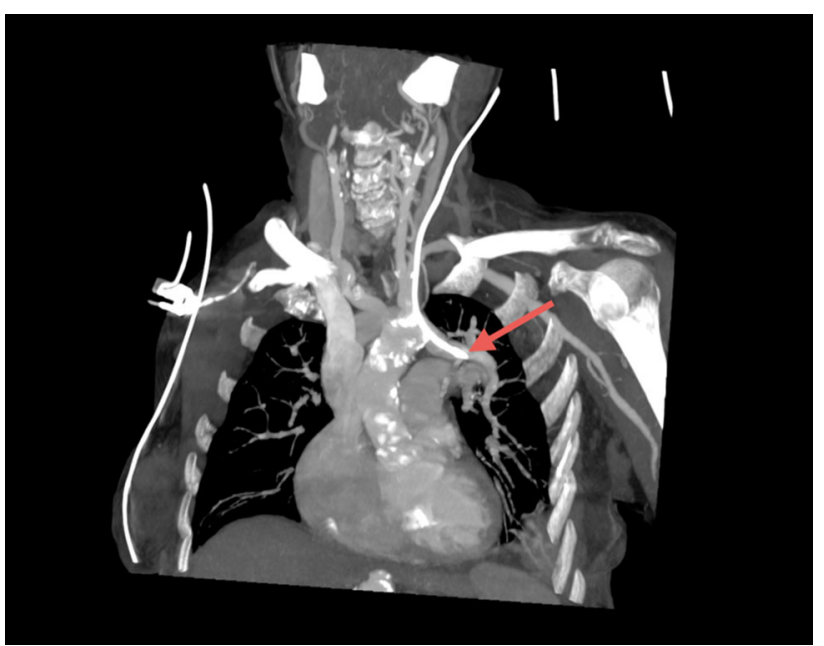

Fig. 2 CT scan showing the catheter tip (arrow) located in the vertical vein

The following chest X-rays showed a catheter above the left main bronchus (Fig. 1a). Because, mean central venous pressure was measured at $23 \mathrm{mmHg}$, a blood gases analysis was performed. The venous sample appeared to indicate a highly oxygenated blood $\left(\mathrm{PO}_{2}=105 \mathrm{mmHg} / \mathrm{PCO}_{2}=42 \mathrm{mmHg}\right)$; on the other hand, measured invasive arterial mean blood pressure was $75 \mathrm{mmHg}$ (arterial $\mathrm{PO}_{2}=70 \mathrm{mmHg} /$ arterial $\mathrm{PCO}_{2}=$ $43 \mathrm{mmHg}$ ). Faced with the present inconsistency despite a catheter apparently in the LIJV, a CT scan was performed and this highlighted that the catheter tip was actually located in a vessel classically named the vertical vein (Figs. 1b, 2). The catheter was then withdrawn without complications. This peculiar form is a rare anatomical shunt named partial anomalous pulmonary return that allows oxygenated and eventually bronchial venous blood drainage into the superior vena cava district.

Conflicts of interest The authors declare that they have no conflict of interest. 